\title{
ON SPATIAL MANAGEMENT PRACTICES: REVISITING THE "OPTIMAL" USE OF URBAN LAND
}

\author{
Marek Ogryzek, PhD \\ Faculty of Geodesy, Geospatial and Civil Engineering \\ University of Warmia and Mazury in Olsztyn \\ e-mail: marek.ogryzek@uwm.edu.pl
}

Radoslaw Wisniewski, assoc. prof., PhD

Faculty of Geodesy, Geospatial and Civil Engineering

University of Warmia and Mazury in Olsztyn

e-mail:danrad@uwm.edu.pl

\section{Tom Kauko, PhD}

Department of Geography

Norwegian University of Science and Technology

e-mail: tom.kauko@port.ac.uk

\begin{abstract}
The article takes a fresh look at the concept of the "optimal" use of urban land. It discusses the procedure for choosing the "optimal" use of land within the context of rational spatial management practices and sets out a model solution for determining "optimal" land use types for given spatial and functional situations. A necessary set of geoinformation for informed decisions on choosing the "optimal" land use type is proposed. The study adds to the available knowledge concerning spatial analyses and simulations of "optimal" zoning processes; in doing so it applies the characteristic matrix method for inducing the optimal use of an area to diagnose the value of urban space and, in this way, to determine the "optimal" use under given circumstances. The article concludes by stating that the algorithm for selecting the "optimal" land use of an area significantly improves the decision-making process when carrying out the transformation of land use - the most important instrument for planning optimisation and organisation.
\end{abstract}

Key words: land management, land use, real estate development, sustainable development.

JEL Classification: C50, R14, R19, R30, Q01.

Citation: Ogryzek M., Wisniewski R., Kauko T., 2018, On Spatial Management Practices: Revisiting the 'Optimal' Use of Urban Land, Real Estate Management and Valuation, vol. 26, no. 3, pp. 24-34.

DOI: $10.2478 /$ remav-2018-0022

\section{Introduction}

Since the 19th century, the dominant view of urban land use has been based on the Ricardian rent concept and the monocentric city model. In this model, transportation frictions for commuting or commerce generate a rent gradient between the city centre and the urban periphery (WILLIAM 2004). Quoting Rossi-Hansberg (ROSSI-HANSBERG 2004), once the optimum is characterized "...we analyse the effect of changes in commuting costs and externality parameters...". In terms of equilibrium and optimal land use, location coincides with market conditions for compensated equilibrium, while also 
establishing the existence and uniqueness of optimal allocation (FuJITA 1989). Location models present cities as economic models, or models of a city's attractiveness potential (gravity models).

In this vein, a number of seminal studies are worth noting. Beckmann (BECKMAN 1952) first introduced the concept of a two-dimensional continuous space into economics. Beckmann and Puu (BECKMANN 1985) studied the formation of urban configuration in a two-dimensional continuous space, focusing on the flows of commodities. Lucus and Rossi-Hansberg (LUCAS, ROSSI-HANSBERG 2002) comprise yet another exceptional urban economic study of a plane city. Puu (PUU 2003) subsequently developed his theory by using various computer simulations to visually represent the significance of their theory. An urban economic model over a continuous plane with a spatial characteristic vector field was introduced by Fujita (FuJITA 1999) and others. It is also worth noting McHarg's (MCHARG 1969) study, as it was of major importance in terms of using the spatial data presented in the form of layers (overlays) in managing environmental resources.

\section{Materials and Methods}

Land use is any kind of permanent or cyclic human intervention to satisfy human needs, whether material or spiritual, or both, from the complex of natural and artificial resources that, together, are called "land" (VINK 1975). Developing Eco-city projects are becoming increasingly prevalent throughout the world, and are often marketed as "new" urban environments focused on achieving sustainable urban living while promoting environmental-economic transitions towards a low-carbon technological and industrial base (CAPROTTI, ROMANOWICZ 2013). The influence of environmental factors in the city development process is becoming just as important as economic factors. This is shown in a number of recent articles on solutions for sustainable development in cities through the protection of the environment; in the contributions to this stream of research, key issues have centred around urban environmental security (HEINRICHS et al. 2013), the reduction of carbon dioxide emissions (BROTO, BulKeley 2013) and the expression of related issues such as the "Creative City" perspective purported by Borén and Young (BORÉN THOMAS, YOUNG CRAIG 2012). A methodology for choosing the optimal use of land was developed by Bajerowski (BAJEROWSKI 1996) in 1996. His method of diagnosing the value of space, based on the characteristic matrix method of inducing optimal use, is an incomplete and insufficient way of taking decisions, because of the absence of compatible model units for all the defined states of land use, like in behaviour analyses and rational choice models (Kakuo, 2015).

The area under study comprises parcels sold by the city of Olsztyn. The raw data was collected from the office of the City of Olsztyn. Such data are collected in the office and, from there, can be easily acquired by any citizen. The data used for the study comprise registered parcels sold in tenders by the City of Olsztyn Administration Office. These are also plots that the Olsztyn local authority wanted to release during the years 2005-2006. In this paper, a matrix of inducing features of optimal use was used, meaning that, for each function of the area, a feature has a favourable or unfavourable influence on it; this is given in points. The optimal function of the parcel is calculated by comparing the values for each of the functions of the area. The basis of this method is a matrix of natural features of the area (Ogryzek, 2007) prepared on the basis of the organizational structure of terrain features and all the factors influencing them.

The tradition presented above by no means represents today's mainstream, even within the land use modelling community. We can note that the optimal/optimization approach is much forgotten; this is much the legacy of the mid 1970s general turn away from the project of developing large scale planning modelling and towards critical and discursive agendas, which also forced the statistical/mathematical approaches to take stock of the contemporary situation and subsequently look at the possibilities to adopt flexible elements. The evolution of computers and datasets has also played a part here, as number-crunching has experienced a renewed interest in recent times. Here we can note some more modern approaches to spatial land use modelling: at least various Spatial Statistical modelling methods (PACE et at. 1998) agent based models for dealing explicitly with complexity, such as Cellular Automata (BENENSON 1998) and Pattern Recognition techniques such as Decision Trees (FAN et at. 2006). However, we have now retrieved the "optimality" concept from the heap of past literature, as we see possibilities for conveniently combining it with judgemental criteria, which we will show later in the present contribution. With the aim of testing our approach, the following thesis is formulated: 


\section{S sciendo}

"Optimal" land use modelling is a valid method of determining land uses for spatial and functional situations, with promising applicability for multiple specific tasks.

This paper ties to the tradition of land use modelling exemplified by the literature referred to above. It is organized in seven sections as follows: following this introduction, Section 2 outlines the essential theoretical underpinnings of "optimal" land use; then, Section 3 introduces the algorithm applied for land use modelling; its application on data from Olsztyn, Poland, is shown in Section 4; the subsequent section, i.e. 5, then compares the results from this exercise with results obtained using Bajerowski's method; Section 6 shows profitability calculations when this algorithm is applied; the final section makes concluding remarks and suggestions for further work.

\section{Optimal land use}

Despite the current relative unfashionable connotations in relation to "optimal" or optimization, we believe such a concept can be used as a building block towards a method for improving the decisions surrounding land use plans and spatial management practices. "Optimal" use of land is most frequently defined as being the use that, given all the physically possible and legally permissible forms of use (i.e. being consistent with the land allocation), results in the highest value of the land (KINZY 1992). Thus, optimal land use can be understood as resulting from human needs and the states of nature, and, consequently, is the sum of the values of the natural and anthropogenous characteristics leading to the highest value of land. A conflict exists between a use that can satisfy the requirements of people, as well as adjusting to environmental conditions and nature's carrying capacity. Bajerowski (BAJEROWSKI 1996) claims that the conflict can be resolved by identifying components that serve to define the "optimal and rational" use of an area. He divided those components into two groups - natural environmental and anthropogenous (i.e. people-centered). The natural environmental conditions change slowly and, in a way, allow for the objective evaluation of different aspects of their functionality. On the other hand, anthropogenous conditions are the result of the living standards in a given area and may change rapidly, thereby making their objective evaluation harder to perform. Defining the character and intensity of functional changes represents the main problem related to the use of the natural environment. The difficulty is to avoid consequences of degradation or destruction of the natural values that are, or used to form, the basis for developing that functionality.

As already mentioned, the data comprises parcels sold by the city of Olsztyn, a medium-sized city in Northeast Poland. The data is collected from the Local Plan, the metrics applied for this study are of two kinds: one set is for natural or what we refer to as anthropogeneous values; the other set is estimates for total economic value - this is estimated from actual sales using simulation techniques. An important feature of this data is that it is weighted by a group of experts; this is explained in the next section.

The process of land use change is continuous. This is caused by the increase in the population and worldwide socioeconomic development. The needs of the people are continually increasing while the carrying capacity of nature is being exhausted. When determining the optimal use of land, one cannot consider human needs without also considering the limitations and facilities of nature, that is to say, maintaining environmental balance. Environmental impact assessment is one of the basic tools of managing environmental protection in the development processes, and, at the same time, matching the principle of sustainable development. In this case, the environment is understood not only as the natural environment, but also as the social environment.

According to the overall principle of optimization, at any given time, every fragment of space has the possibility of obtaining the state of optimal use. However, the presence of appropriate characteristics within a given space does not necessarily lead to the assumption that the space will be used appropriately. It can be argued that the probability of the current use to be adjusted to grow closer to the optimal use is high, although it is left largely to chance whether the optimal use will ever be accomplished (ZUKAV 1995). Every use of land is, at the same time, also a result of the demand for that particular use of space, at least in principle. Demand causes areas possessing appropriate characteristics to be chosen for a particular use, or else it becomes necessary to transform the characteristics to accomplish the optimal use. In this way, the state of use can otherwise be understood as the management of space (BAJEROWSKI 2003). The states of using land can be characterized according to the attributes as the current use, the best use of the area considering its internal characteristics, or the best intended use of the area (HOPFER et al. 1982). 
By accumulating characteristics in a specific place, space attracts certain events, or permits their interpretation. The attributed set of objective characteristics has no value by itself, as value depends on a person's, or other actor's (firm, corporation, public body, etc.), specific intentions. Here we must note that, in Neoclassical economics, intentions equal actual choices, whereas in more behavioural theorization, intentions are understood as a broader and more abstract concept than the actual choices made. The specific collection of geoinformation (spatial characteristics) for a given place creates a certain potential that can be measured by the probability of events occurring (optimal area use), which those spatial characteristics support. Thus, the task is to match the attractiveness of the space with the constraints posed by the specific situation in terms of the geographic and institutional constraints. The corollary here is to select a valid metrics for each dimension - environmental and economic. The next section explains these steps in detail.

\section{Algorithm of the optimal use of land}

Discussed above is the rationale for changes in land use and spatial management practices. Here we examined many points of view, mainly with environmental, economic and demographic significance. The next issue now is finding the analytical basis for the suggested changes. In order to determine the optimal use of an area, particularly within urban areas, many tasks must be undertaken at the stage of studies and analyses, and the possibility of generating spatial conflicts must be minimised. The optimal use of an area is the state where the sum of natural and anthropogenous values for a given land use category is higher than the sum of the natural and anthropogenous values of the current land use, and where the economic value after transformation is the highest when compared to the other land uses of the area.

The mathematic notation for the conditions of the optimal function of an area, as well as the tools for determining the necessary parameters (natural, anthropogenous and economic values) were developed using linear programming.

After defining the metrics as explained in the previous section, the computational method needs to be designed. The procedure for choosing the optimal use of land in the rational planning of space management should progress according to the following stages:

I. Designing an optimal land use model.

II. Using the modified characteristic matrix method (geoinformation) of inducing the optimal use of the area.

Stage 1 - Model solutions of choosing the optimal use of land.

If the "optimal" use means the most rational use, then, based on rational decisions theory analysis, it is possible to determine postulates for the rational "optimal" use of an area. The Rational Decisions Theory has been developed mostly within the tradition of operational studies. It is a component of praxeology - the science of rational activities of human groups. This theory formulates rational (optimal) methods of problem solving basing on rational postulates. The most important task, and at the same time the toughest one, is to define which conditions have to be met in order to make the decision rational. Until recently, this problem had not been satisfactorily solved. However, according to Kozielecki (Kozielecki, 1997), two postulates appear to have been approved; these postulates refer to consequence and maximization. In this research, the maximization postulate was used in order to show land use as a mathematical function.

The two postulates form the rational decision theory, and this is considered to be a sufficient assumption to use when applying this theory.

The eclectic body of literature on this postulate is well-established. Kozielecki has solved what is referred to as "the optimal diet problem". This problem means finding the optimal diet for a group of people with the same characteristics (body, lifestyle, etc.). Ogryzek, in 2007, modified his method and adjusted it to land use optimization. Individual dietary components were changed into area characteristics, which were weighted according to the matrix of natural characteristics, inducting optimum use of land developed by Bajerowski (Bajerowski, 1996) and Ogryzek (Ogryzek, 2007). This system is based on two essential postulations, which are explained below. Matrices are available in Ogryzek's paper (Ogryzek 2007).

Postulate 1 - A given area can be transformed to the optimal land use category if two conditions of optimal decision rationality (area land use optimality conditions) are satisfied: 


\section{S sciendo}

1. The natural or anthropogenous values for the given land use are equal to or higher than the natural or anthropogenous values for the current land use type; this is for parcels sold by the city.

2. The total economic value after transformation, as well as the total natural and anthropogenous value, is the highest when compared to the other land uses of the parcel; this is an approximation of the study area based on the data on parcels sold by the city as mentioned above.

Linear programming is applied to propose the following mathematic notation for determining the conditions of the optimal land use of an area. In analyzing the given problem, a system of inequalities is proposed for optimizing the spatial process in space management. Let us assume that:

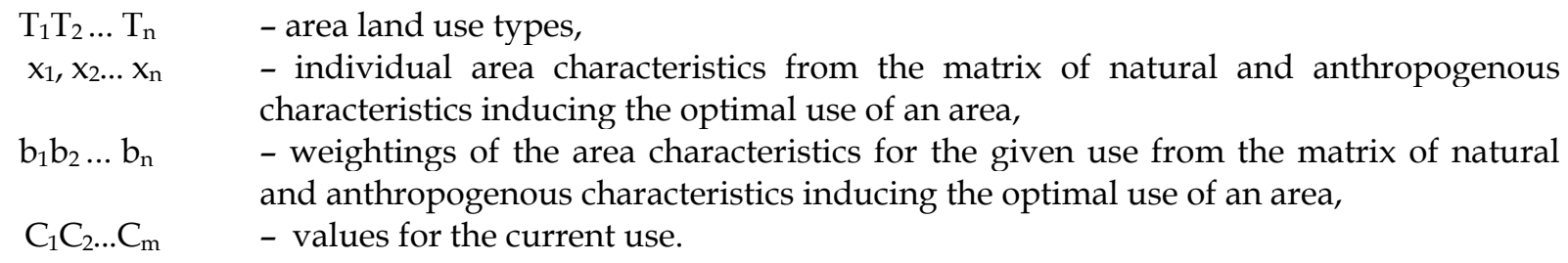

The system of inequalities must satisfy Condition 1 (Ogryzek, 2007) based on Kozielecki (Kozielecki, 1997):

$$
\begin{aligned}
& b_{11} x_{1}+b_{12} x_{2}+\ldots+b_{1 n} x_{n} \quad C_{1} \\
& b_{21} x_{1}+b_{22} x_{2}+\ldots+b_{2 n} x_{n} \geq C_{2} \\
& \ldots \ldots \ldots \ldots \ldots \ldots \ldots \ldots \ldots \ldots \ldots . \\
& b_{m 1} x_{1}+b_{m 2} x_{2}+\ldots+b_{m n} x_{n} \geq C_{n}
\end{aligned}
$$

If the value of a land use category other than the current one satisfies the condition above (hereafter: Condition 1), then, from the perspective of rationality, that land use category should be assumed. Satisfying those postulates only is, however, insufficient because the postulate of the maximum objective function, according to which the area function has to fulfil the following condition (Condition 2), would also have to be satisfied (Ogryzek, 2007) based on Kozielecki (Kozielecki, 1997): If $\mathrm{k}_{1} \mathrm{k}_{2} \ldots \mathrm{k}_{\mathrm{n}}$ is $\mathrm{W}_{\mathrm{k}}$ - land market value indicator, then:

$$
\begin{aligned}
& U=k_{1}+\left(b_{11} x_{1}+b_{12} x_{2}+\ldots+b_{1 n} x_{n}\right)=\max \\
& U=k_{2}+\left(b_{21} x_{1}+b_{22} x_{2}+\ldots+b_{2 n} x_{n}\right)=\max \\
& \ldots \ldots \ldots \ldots \ldots \ldots \ldots \ldots \ldots \ldots \ldots \ldots \ldots \ldots \ldots \ldots \ldots \\
& U=k_{n}+\left(b_{m 1} x_{1}+b_{m 2} x_{2}+\ldots+b_{m n} x_{n}\right)=\max
\end{aligned}
$$

After this, the "optimal" land use parameters require standardization to allow for their more objective comparison and analysis.

Postulate 2 - The given area may be transformed to a suboptimal land use category, or may be left in its current use if rational environmental premises or social needs allow.

Environmental premises characterize a situation where the appropriate circumstances give us reasons to leave the land use as it is, or change it to a more ecologically friendly one. This happens, for example, when protected areas connected with the "Natura 2000" program are incorporated into local zoning plans. Social needs, in turn, refer to social expectations. These can be expressed, for example, during public consultations, such as when deciding on the location of a park, playground, school, and so forth. That is why, in an ideal algorithm, the land use is to be considered both compatible with the natural and anthropogenic characteristics matrix and economically justified. However, there are some situations when exceptions occur, such as protected areas, where no land use changes should be made, property development areas or public investments, such as shops in housing areas. Our data also includes such cases.

This postulate offers the possibility of changing the land use of an area in cases justified by cultural or religious considerations, disasters or other factors justifying the rejection of the optimal conditions of an area's land use based on Postulate 1. In justified cases (because of public interest, economic conditions, maintaining the environmental-economic balance, cultural conditions, disasters, etc.), spatial management analysis imposes the need to change an area's land use regardless of whether mathematic systemic assumptions are satisfied or not. If the conditions for the "optimal" land use of an area are not satisfied (this is Postulate 1: such a situation can happen when the land use is optimal but will not generate profit for the community. The parcel can be sold with different land use if needed, e.g. a new road or sewage treatment), then the highest sum of the natural, anthropogenous 
and economic values after transformation should be chosen as the solution. If environmental premises for maintaining a parcel in its current land use exist, the parcel should be left in its current state of land use, or its land use should be changed to one that is friendly to the ecosystem. This leads to the conclusion that the specification and the individual circumstances of disposing of an area influences the decision on applying the transformation process, and that transformation, as an instrument of space optimization, should be the fundamental component in each method of determining the optimal use. The fundamental goal of spatial management, i.e. protecting the defined values of a space, along with its rational development, by stimulating economic processes should not be forgotten. Protective activities include maintaining the balance between the natural elements of the environment and the products of human activity.

On the other hand, spatial development is transformation activity linked to what we refer to as the new directions of socioeconomic development. It can be argued that different socioeconomic groups of people want to make their lives better through the development of their functional and accessible situations, such as having a shorter route to the work-place, new playgrounds in the area, hospitals and other such matters, which are prosaic, but very important to the inhabitants.

Stage 2 - Applying the characteristic matrix method for inducing the optimal use of a parcel.

The area characteristics necessary to determine the optimal use of land, as well as the land value indicator - a variable to determine the optimal land use - are obtained by applying the characteristic matrix inducing optimal use, modified by Ogryzek (OGRYZEK 2007). Every cartographically identifiable characteristic that is present in the given area exerts its own force on the area to take on the best use of space from the perspective of that characteristic and the current demand. That force maximises the probability of the "optimal" use of space emerging at a specific time. The maximum value of that probability indicates one form of use from all the probable forms. Each of those forms is characterised by a given probability of occurrence in the given smaller basic field, but only the form showing the highest probability value satisfies the characteristics of the "optimal" use (BAJEROWSKI 1996). In the case of each of the land uses of an area, a given characteristic has a positive or negative influence, which is reflected in the form of points. The "optimal" land use of a given area of land is worked out by comparing the values for each of the area's land uses. On the other hand, Ecological Macroeconomic Models (HARDT, O'NeILL 2017) or models from evolutionary and complexity economics are used in economics (Foxon et al., 2013).

This is exactly Bajerowski's method. A parcel is a primary feature that is weighted (that is used later in the mathematic algorithm in Kozielecki's method). Every land use has a given point (plus means beneficial impact, minus adverse). For example, a slope factor from 0 to 3 results in +16 points for agricultural land use (arable land) and -14 for recreational land use (recreation without development permission). Finally, the results can be compared in numerical form for any purpose. However, inference on the basis of this method is false because it was noted that this method lacks anthropogenic features, which also have an influence on the choice. Therefore, Ogryzek developed his own matrix which has been incorporated into the choice of the model of optimal land use of the site. In addition, it was supplemented by a method of determining the financial consequences of changing the use of the land.

The method employed is based on the matrix of natural characteristics of the area (BAJEROWSKI 1996). The matrix of anthropogenic characteristics inducing the optimal use of an area was developed to allow the issue to be analyzed more comprehensively. Ogryzek (OGRYZEK 2007) calls it the "local characteristic matrix" influencing the potential attraction of the choice. The optimal use of an area will be represented by the sum of the value of the natural and anthropogenic characteristics for the individual land uses of the area. An evaluation of the intensity of the influence of the characteristics on the value of land is difficult because human preferences have the largest impact on its image, along with the specific factors of the area and the individual circumstances of disposal, which was used to get nformation about people's needs in Olsztyn. Thus, the developed evaluation system must be easily updatable and adjustable.

At any given time, each parcel has the potential to achieve "optimal" use. However, every change in the use of an area should be preceded by the determination of the profitability of that change. It may happen that the difference between the value of land under optimal use and its value under the current use will be smaller than the cost of transformation (e.g. the cost of preparing a new local zoning plan, the cost of constructing technical infrastructure, and the cost of improving the roads). In 


\section{$\$$ sciendo}

that case, any change of the current use would be unprofitable. The profitability of transformation is represented by the difference between the value of the area in the case of the given land use and the costs of transformation to that function land use function (Bajerowski, 1996).

$$
\mathrm{O}_{\mathrm{T}}=\mathrm{W}_{\mathrm{T}}-\mathrm{K}_{\mathrm{T}}
$$

where:

$$
\begin{array}{ll}
\mathrm{O}_{\mathrm{T}} & \text { - use transformation profitability, } \\
\mathrm{W}_{\mathrm{T}} & \text { - area value after transformation, } \\
\mathrm{K}_{\mathrm{T}} & \text { - transformation costs. }
\end{array}
$$

The authors propose using the transaction price indicator (parcel value) obtained from a computer simulation of real property sale by tender to determine the comparative unit, which can be computed in a special software developed for this purpose by Ogryzek. This represents a modification to the formula for the expected value of the game (KAMIŃSKA 2003).

$$
\mathrm{W}_{\mathrm{k}}=\left(\mathrm{C}_{\mathrm{T} 1}, \mathrm{C}_{\mathrm{T} 2}, \mathrm{p}_{1}, \mathrm{p}_{2}\right)=\mathrm{p}_{1} \mathrm{C}_{\mathrm{T} 1}+\mathrm{p}_{2} \mathrm{C}_{\mathrm{T} 2}
$$

where:

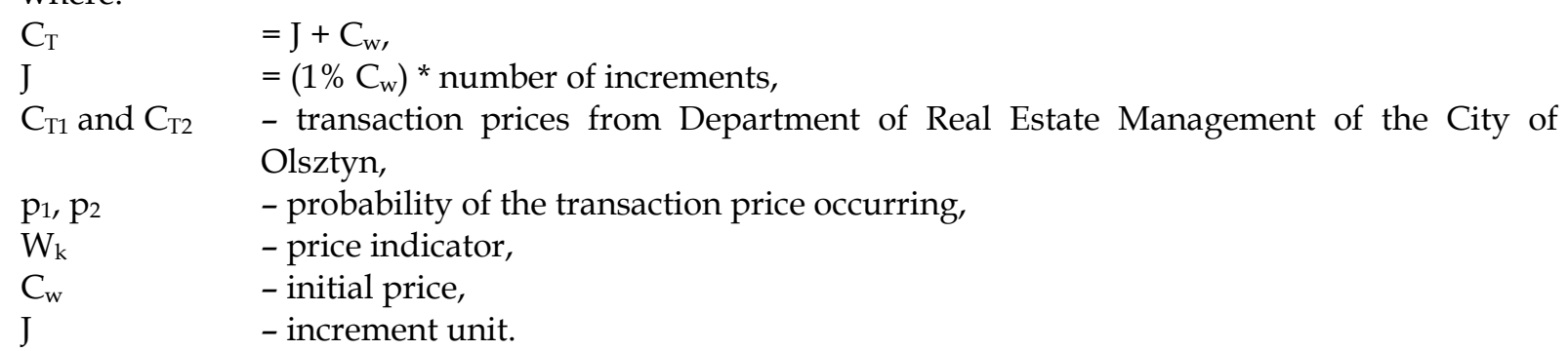

Game variances should be calculated in order to obtain a more precise risk measure. Situations when the results of certain monetary values appear with a different probability are called games. Hence, we have the expected value - the average payoff obtained by repetition of the sales area in a computer simulation. The variance of the game (VG) is a measure of the variability of results (riskiness of the game). VG is the sum of the squared deviations of the results of the game from its expected value, weighted by the probability of the occurrence of the results, that is:

$$
W G=\sum_{s=1}^{n} \mathrm{p}_{\mathrm{s}}\left(\mathrm{w}_{\mathrm{s}}-\mathrm{W}_{\mathrm{k}}\right)^{2},
$$

where:

$\begin{array}{ll}\text { Ws } & \text { - game result, } \\ \mathrm{p}_{\mathrm{s}} & \text { - probability of occurrence }\end{array}$

The higher the deviation from the result, the riskier the game. The application selects the price indicator in the case when of the risk obtained from the modification of the formula for variances of the game is the lowest (OGRYZEK 2007; KAMINSKA 2003).

The parcel value for all the land uses is determined as the most probable real property sale price in the tender procedure. A comparison of the indicators for all the parcel's land uses allows for the potential profits from the disposal of the real property through tender to be determined for each of the uses. In that way, it is possible to design a projected model of comparative units for all the land uses of the parcel.

\section{Results and discussion}

As mentioned at the outset, the data used for the study comprise registered plots of land that the Olsztyn local authority wanted to release during the years 2005-2006. Those plots were sold in tenders by the City of Olsztyn Administration Office. Archival information contained descriptions of the real property and details on the tender. Site inspections and layers of digital maps from the EWMAPA software provided further sources of information from the land use registry stored for every parcel in the city. The determination of the optimal use parameters and an analysis of the results aimed at selecting the optimal use were conducted according to the procedure proposed for determining the optimal use of the parcel involving the following steps:

Stage 1. Geoinformation (characteristics) were gathered for each parcel (cadastral data, site inspection data, City of Olsztyn's geographic information system data). 
Stage 2. Parameters of optimal use were determined.

Stage 3. Results were analyzed to select the optimal use (using the first rationality postulate)

Stage 4. The land use of choice was justified based on the characteristics of the parcel (using the second rationality postulate).

The City of Olsztyn's Administration Office put 84 parcels of land for sale. Their baseline status was described as the current land use. During the analysis, 65 plots were identified within the studied area for which the current use was "suboptimal". Analyzing the results, we conclude that the demand for transformation to the optimal use existed in the studied area. Naturally, before taking any decision on whether to carry out a change in use, the second optimization rationality postulate, as set out above, should be applied. Based on the parcel characteristic matrix, it was concluded that the transformation to optimal land use was not possible in the case of all the plots. This situation is caused by the demand for residential land use. The transformation of some of the plots into an intermediate land use (i.e. a construction plot with the possibility of providing small-scale services) seems justified, because it is consistent with the algorithm. The next option was to allocate land for the construction of a mini-market or to build commercial facilities on the ground floor and residential units above them along the main road. We compare prices (determined by the optimal use of urban land) obtained by Bajerowski's classical method and the proposed algorithm of optimal use of land. We define the simulator efficiency factor (price index) $\mathrm{W}$ as the ratio:

$$
\mathrm{W}=\mathrm{C}_{\mathrm{S}} / \mathrm{C}_{\mathrm{T}}
$$

where Cs is the simulated transaction price and CT denotes the actual transaction price. If $\mathrm{W}$ is close to 1 then the simulated transaction price closely approximates the market price; thus it indicates the usefulness of the simulator. We define the simulator efficiency factor (price index) $\mathrm{W}^{\prime}$ as the ratio too:

$$
\mathrm{W}^{\prime}=\mathrm{C}_{\mathrm{B}} / \mathrm{C}_{\mathrm{T}}
$$

where $C_{B}$ is the transaction price computed using Bajerowski's method, and $C_{T}$ denotes the actual transaction price.

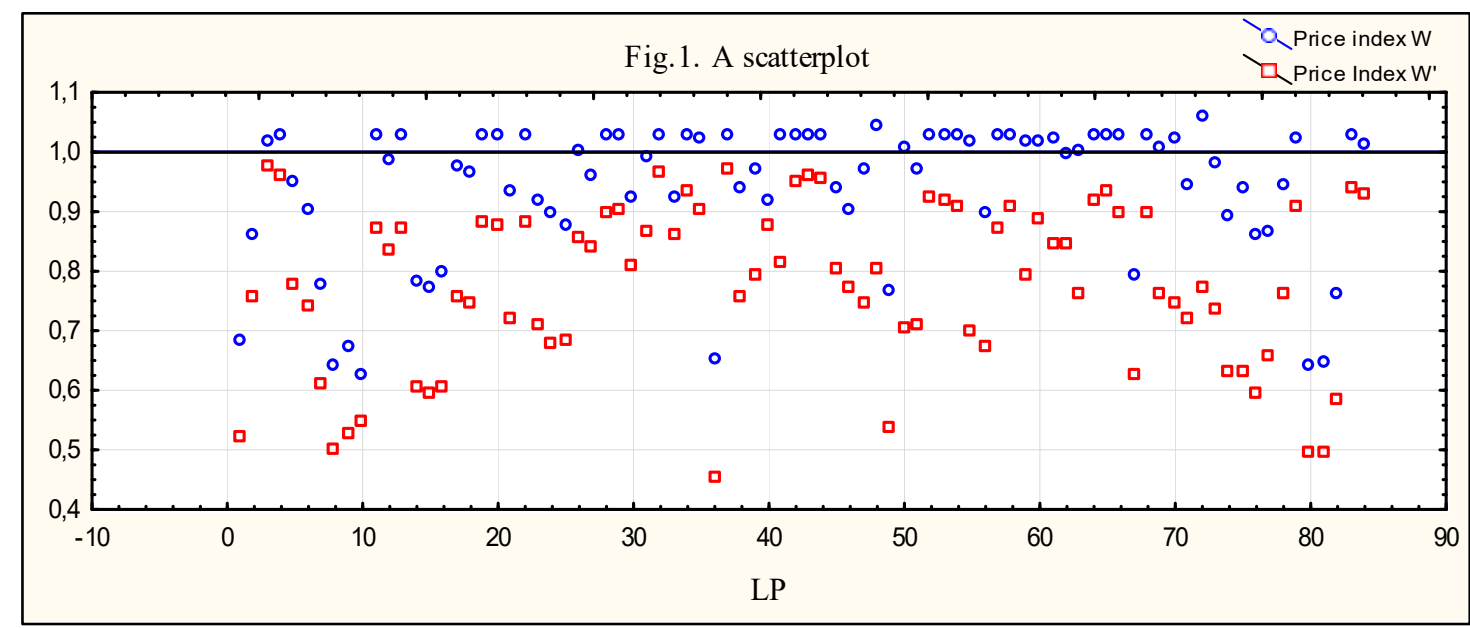

Fig. 1. Chart showing the results obtained by both methods. Source: own study.

Figure 1 shows the price indexes $W$ (our method) and $W^{\prime}$ (Bajerowski's method) for a test group of 84 plots in the Olsztyn city area. It is clear that, on average, $W$ is closer to the optimal line (if $W=1$ then the estimated price is equal to the market value of the given land plot) than $W^{\prime}$ with the lesser standard deviation. $\mathrm{W}=0.94+/-0.12 . \mathrm{W}^{\prime}=0.77+/-0.13$.

Thus, the comparison indicates that our method performs better than Bajerowski's method. Profitability was determined by estimating the probable profit after transformation for the entire area under study. We decided, however, that social needs are an equally important parameter. Hence, within the studied area, some of the functions of parcels should be transformed into the optimal land use, while some should be transformed to land uses satisfying social needs. The remaining real properties should be maintained in their current land use, as that land use is optimal. Considering the environmental and social needs (rationality postulate 2 of the optimal area land use), the most 


\section{S sciendo}

probable profit will amount to ca. EUR 12,000. It is economically justified to transform to the optimal land use those real properties whose sale would generate the highest financial benefits to the local authority. In that way, we minimize the losses caused by the transformation to the function satisfying social needs. For example: the city of Olsztyn has parcels to sell, and sells them with some already intended property use. This can be the current land use, but this is sometimes not as profitable as it could be. This is where "better" land use can be computed. For example, the city wants to expand to the west, because there are good agricultural parcels in the east. By selling parcels in the east the city may earn money, but it will not be sold for the specific land use (non-agricultural). If the city sells these parcels it will lose it, unless their intended use is changed, e.g. to building. Furthermores, some parcels in this area must be chosen for public use, such as schools or parks. Here, the city can choose the parcels to sell with the highest profits, leaving those with the lowest to the public. The city designates the places with high value and also selects the best land use for them.

\section{Conclusions}

Spatial management practices have a long-standing tradition in land use modelling - especially in the urban context. With this tradition as a backdrop, the aim of the study was to examine the usefulness of a land use modelling approach based on the concept of "optimality" and a set of mathematical algorithmic principles. An analysis of the results of the exercises above showed that the thesis formulated at the outset can be verified positively. The results point to the following conclusions.

Appropriately gathered area characteristics form the basis for efficient space management. Land use transformation is the main instrument of efficient space management. That operation is justified only in cases when it is economically profitable - exceptions are for the protection of the natural environment or the satisfaction of social needs, as had been explained. The profitability of that operation can be analyzed and estimated using the algorithm for the optimal use of the area, as proposed in the paper. The optimal function choice tool is useful in the process of developing spatial development plans. It allows a solution that is the most beneficial for the given area to be selected. This helps to develop solutions that take into account not only economic aspects, but also environmental aspects and human needs. The proposed system may be applied in different scales and at different levels of detail of spatial analyses.

The transformation of land use is one of the main tools in planning spatial management. Being the goal and outcome of spatial planning, it must optimize the relationships between natural value, environmental value and economic value, as well as social need. The main goal of spatial management, i.e. the protection of specific values of the space and rational spatial development, must not be forgotten. Protective activities aim at maintaining the balance between the natural elements of the environment and the products of human activity. Spatial development, on the other hand, represents transformation activities related to ongoing trends of socio-economic development. The optimality of land use thus results from the balance between the criteria of its evaluation.

Expanding the systems of geoinformation with the proposed land characteristics will allow spatial analyses and simulations of space use optimization processes. In the future, applying these independent tools could be developed based on such an algorithm, which is likely to cut down the costs and time required for developing optimal conditions for the choice of function and location of such things as roads, tunnels, bridges, recreational areas, schools and kindergartens, etc. Location and spatial dislocation of the population are the basic tasks of planners and urban planners, and transformation is an inevitable and necessary subject for taking decisions (managing space). The use of that operation must be justified. On the basis of the promising results obtained, we suggest that the methods and tools proposed in the paper should form an inseparable component of every contemporary Spatial Information System. The system supports spatial planning, the registration of objects and spatial installations. At the same time, it is a tool for performing operations on spatial data and, primarily, the digital collection of maps.

The expected results of applying the characteristic matrix include securing consistent, current and reliable spatial and descriptive data and information in the city studied. It is also important to improve the flow of information, and increase the effectiveness of work along with the effectiveness and transparency of taking public decisions. Other crucial aspects were providing an assurance of general access to data and holding a public evaluation of decisions taken in order to improve the effective use of funds in the economy. Lastly, it is also worth considering how best to create conditions for satisfying European commitments and to explore possibilities for obtaining benefits from accession 
to the European Union.

In order to use the modified Bajerowski's method, a local characteristics matrix should be developed for the study area. Information about land usage in the city can be accessed using GIS. A system, placed on the server, can "ask" users to complete a survey and, based on its results, an anthropogenic features matrix can be developed. Residents can also indicate, using WEB GIS space from postulate 2, those parcels where they would like to preserve valuable nature or indicate the places where they would like to locate public investments.

\section{References}

BAJEROWSKI T., 1996, Metodyka wyboru optymalnego użytkowania ziemi na obszarach wiejskich, (Methodology for Selecting Optimal Land Use in Rural Areas), Acta Acad. Agricult. Tech. Olst. Geodaesia et Ruris Regulatio, No. 26, Supplementum B.

BAJEROWSKI T., 2003, Podstawy teoretyczne gospodarki przestrzennej i zarzadzania przestrzenia, (Theoretical Foundations of Spatial Development and Spatial Management), Wydawnictwo UWM w Olsztynie.

BECKMAN M. J., 1952, A Continuous Model of Transportation", Econometrica 20, pp. 642-660.

BeCKMann M.J., PuU T., 1985, Spatial Economics: Potential, Density, and Flow, North-Holland Publishing Company.

BENENSON I. 1998, Multi-Agent Simulations of Residential Dynamics in the City, Computers, Environment and Urban Systems 22 (1), pp. 25-42.

BORÉN T., Young Craig, 2012, Getting Creative with the 'Creative City'? Towards New Perspectives on Creativity in Urban Policy. International Journal of Urban and Regional Research, Volume 37, Issue 5, pp. 1799-1815.

Broto V., BulKeley H., 2013, Maintaining Climate Change Experiments: Urban Political Ecology and the Everyday Reconfiguration of Urban Infrastructure, International Journal of Urban and Regional Research,

CAPROTTI F., ROMANOWicz J., 2013, Thermal Eco-cities: Green Building and Urban Thermal Metabolism, International Journal of Urban and Regional Research, 8 JUL.

FAN, G.-ZH., ONG, S. E., KOH, H. CH. 2006, Determinants of House Price: A Decision Tree Approach, Urban Studies 43 (12), pp. 2301-2315.

Foxon T., KOHLER J., Michie J., Oughton C., 2013, Towards a New Complexity Economics for Sustainability, Cambridge Journal of Economics 37(1), pp. 187-208.

FujiTA M., 1989, Urban Economic Theory: Land Use and City Size, Cambridge University Press.

FujitA, M., KRUgman, P., Venables, A., 1999, The Spatial Economy, MIT Press, Cambridge.

HARDT L., O'Neill D., 2017, Ecological Macroeconomic Models: Assessing Current Developments, Ecological Economics, 134, pp. 198-211.

HeinRICHS D., KRellenberg K., Fragkias M., 2013, Urban Responses to Climate Change: Theories and Governance Practice in Cities of the Global South, International Journal of Urban and Regional Research.

HOPFER A., CYMERMAN R., NOWAK A., 1982, Ocena i waloryzacja gruntów wiejskich, (Evaluation and Valorisation of Rural Land) PWRiL, Warszawa,

KAMIŃSKA T., 2006, <http://ekonom.univ.gda.pl/mikro/skladosobowy/Kaminska/SD/Teoria\%20ryzyka_popr1.pdf>.

KAKUO T., 2015, Debates in the Methodology of Economics and the Value of an Environmental Amenity, Pacific Rim Property Research Journal 12(4)

KINZY S. A., 1992, Attribute Forecasts Based on Land Residual Maximization, Land Economics. 68 (4): pp. 380-396.

KozIELECKI J., 1997, Psychologiczna teoria decyzji, (Psychological Decision Theory), Wyd. 2 PWN, Warszawa: 14-93.

LUCAS R.E., ROSSI-HANSBERG E., 2002, On the Internal Structure of Cities, Econometrica 70 (4), pp. 14451476.

MCHARG I. L., 1969, Design With Nature, New York, Wiley, pp. 4- 25.

OGRYZEK M., 2007, Weryfikacja metodyki wyboru optymalnego użytkowania ziemi wg Bajerowskiego dla potrzeb zarzadzania przestrzenia planistyczna, (Verification Methodology of Selecting the Optimal Use of Land by Bajerowskiego for Space Management Planning,) Acta Scientiarum Polonorum, Administratio Locorum 6 (2), pp. 19-34. 
PACE R. K., BARRy R., ClapP J. M., Rodriguez M. 1998, Spatiotemporal Autoregressive Models of Neighborhood Effects, Journal of Real Estate Finance and Economics, 17 (1): 15-33.

PuU T., 2003, Mathematical Location and Land Use Theory; An Introduction, Second Revised and Enlarged Edition, Springer-Verlag.

Rossi-HANsBerg E., 2004, Optimal Urban Land Use and Zoning, Review of Economic Dynamics, 7, pp. 69-106.

William C. W., 2004, Commuting, Congestion, and Employment Dispersal in Cities with Mixed Land Usee. Journal of Urban Economics 55, pp. 417-438.

VINK, A. P. A., 1975, Land use in advancing agriculture, Springer-Verlag Berlin Heidelberg, New York.

ZukAv, G. 1995, The Dancing Wu Li Masters. An Overview of the New Physics, New York: Bantam Books, Dom Wydawniczy Rebis, Poznań. 